\title{
JURNAL KESEHATAN MASYARAKAT
}
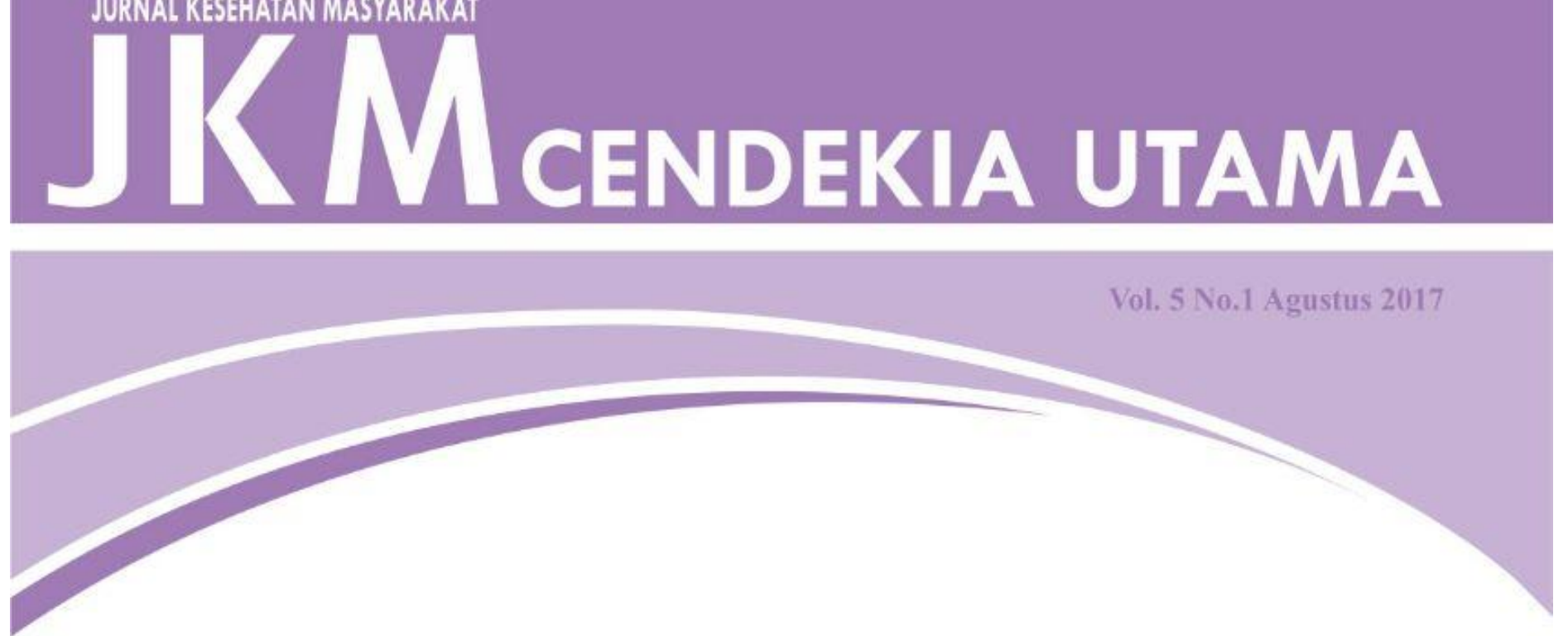

RISIKO INFEKSI MENULAR SEKSUAL PADA ANAK BUAH KAPAL DI PELABUHAN JUWANA PATI Risna Endah Budiati

PENGARUH TARIAN TEPUNG SELACI PUPUT TERHADAP PENINGKATAN PENGETAHUAN, SIKAP DAN PRAKTIK PADA SISWA SEKOLAH DASAR Ervi Rachma Dewi

ANALISIS KUALITAS FISIK AIR DI DESA CRANGGANG KECAMATAN DAWE KABUPATEN KUDUS David Laksamana Caesar, Eko Prasetyo

HUBUNGAN TINGKAT PENGETAHUAN PERAWAT TENTANG PATIENT SAFETY TERHADAP PENERAPAN SASARAN V (PENGURANGAN RESIKO INFEKSI TERKAIT PELAYANAN KESEHATAN) Edy Bachrun

KUALITAS FISIK JAMBAN KELUARGA DAN KEJADIAN DIARE DI DESA BERAN, NGAWI Riana Maharendrani 
Vol. 5, No. 1

P-ISSN 2338 -6347

Agustus, 2017

E-ISSN 2580-992X

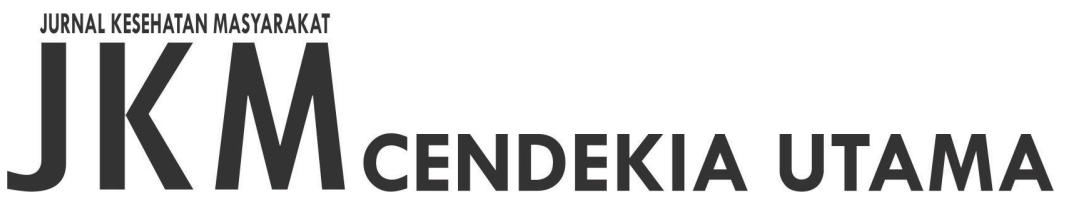




\section{JKM cendekia utama}

\section{Editor In Chief}

Eko Prasetyo, SKM, M.Kes, STIKES Cendekia Utama Kudus, Indonesia

\section{Editorial Board}

Sri Wahyuningsih, SKM, M.Gizi, STIKES Cendekia Utama Kudus, Indonesia Risna Endah Budiati, SKM, M.Kes (Epid), STIKES Cendekia Utama Kudus, Indonesia

Niken Puspitowati, SKM, M.Kes, STIKES Cendekia Utama Kudus, Indonesia Ervi Rachma Dewi, SKM, M.Kes, STIKES Cendekia Utama Kudus, Indonesia David Laksamana Caesar, SKM, M.Kes, STIKES Cendekia Utama Kudus, Indonesia

\section{Reviewer}

Sigit Ari Saputro, SKM, M.Kes, Universitas Airlangga Surabaya, Indonesia dr.Mahalul Azam, M.Kes, Universitas Negeri Semarang, Indonesia Eti Rimawati, SKM, M.Kes, Univeritas Dian Nuswantoro Semarang, Indonesia Didik Sumanto, SKM, M.Kes(Epid), Universitas Muhammadiyah Semarang, Indonesia

\section{English Language Editor}

Arina Hafadhotul Husna, S.Pd, M.Pd, STIKES Cendekia Utama Kudus, Indonesia

\section{IT Support}

Susilo Restu Wahyuno, S.Kom, STIKES Cendekia Utama Kudus, Indonesia

JKM (Jurnal Kesehatan Masyarakat) Cendekia Utama merupakan jurnal ilmiah dalam bidang kesehatan masyarakat yang diterbitkan oleh Program Studi S1 Kesehatan Masyarakat STIKES Cendekia Utama Kudus secara berkala dua kali dalam satu tahun 
Vol. 5, No. 1

Agustus, 2017

\section{DAFTAR ISI}

Halaman Judul....................................................................... i

Susunan Dewan Redaksi .......................................................... ii

Kata Pengantar................................................................... iii

Daftar Isi ................................................................................. iv

Risiko Infeksi Menular Seksual Pada Anak Buah Kapal Di Pelabuhan Juwana Pati ..........................................................

Pengaruh Tarian Tepung Selaci Puput Terhadap Peningkatan Pengetahuan, Sikap, Dan Praktik Pada Siswa Sekolah Dasar ........... 12

Analisis Kualitas Fisik Air Desa Cranggang Kecamatan Dawe Kabupaten Kudus ............................................................... 26

Hubungan Tingkat Pengetahuan Perawat Tentang Patient Safety Terhadap Penerapan Sasaran V (Pengurangan Resiko Infeksi Terkait Pelayanan Kesehatan)

Kualitas Fisik Jamban Keluarga Dan Kejadian Diare Di Desa Beran, Ngawi

Lampiran

Pedoman penulisan naskah JKM 


\title{
KUALITAS FISIK JAMBAN KELUARGA DAN KEJADIAN DIARE DI DESA BERAN, NGAWI
}

\author{
Riana Maharendrani \\ Prodi Kesehatan Masyarakat STIKES Bhakti Husada Mulia Madiun \\ prodikesmasbhm@gmail.com
}

\begin{abstract}
ABSTRAK
Diare masih menjadi 10 besar penyakit tahun 2015 di Kabupaten Ngawi dan Desa Beran memiliki insiden tertinggi periode Maret-Mei 2015. Pemerintah Kabupaten Ngawi sudah mendeklarasikan Open Defecation Free (ODF), namun kasus diare masih tinggi. Tujuan penelitian ini mengetahui hubungan kualitas fisik jamban keluarga dengan kejadian diare di Desa Beran Kabupaten Ngawi. Penelitian ini merupakan penelitian analitik dengan pendekatan cross sectional. Populasi pada penelitian ini adalah kepala rumah tangga yang mempunyai jamban di Desa Beran. Sampel penelitian ini 98 responden dengan teknik cluster sampling. Pengumpulan data menggunakan checklist, dan dianalisis dengan chi square. Hasil penelitian ini menunjukan tidak ada hubungan antara kualitas fisik jamban dengan kejadian diare $(p=0,328)$. Sebagian penduduk Desa Beran memiliki kualitas jamban dengan kriteria sehat, sebagian kecil pernah mengalami diare selama 3 bulan terakhir dan kejadian diare di Desa Beran. Sebaiknya masyarakat meningkatkan kualitas jamban yang dimiliki agar penularan penyakit diare dapat dicegah.
\end{abstract}

Kata Kunci : Kualitas fisik jamban, diare.

\begin{abstract}
Incident of Diarrhoea became the top ten of desease 2015 In Ngawi and Beran had highest incident in March-May 2015. Ngawi District Government had declared Open Defecation Free (ODF), but the case of diarrhea was still high. The aim of this study was to determined the association of Family's toilet with Case of Diarrhoea in Beran, Ngawi. This study was an analytical research with cross sectional approach. The population in this study was a head of household or representing that have toilet in the Beran. The sample were 98 respondents taken by cluster sampling. The data collection using checklist and analyzed by chi square. The result of this research showed that there was no association between of toilet quality with Diarrhoea case $(p=0,328)$. More people in Beran had toilet with healthy quality, a small portion had experienced diarrhea during the last 3 months and the village Beran was not caused by the quality of toilet. Finally, strongly suggest that people should increase the quality of toilet to prevent the diarrhoea spreading.
\end{abstract}

Key words : Toilet quality, diarrhoea case. 


\section{PENDAHULUAN}

Penyakit diare merupakan penyakit yang berbasis lingkungan. Beberapa faktor lingkungan yang tidak memadai sarana air bersih, air tercemar oleh tinja, kebersihan perorangan, dan lingkungan yang jelek, termasuk kualitas fisik jamban. ${ }^{[1]}$ Berdasarkan data Puskesmas Ngawi, kasus diare selama tiga bulan terakhir meningkat sebanyak 24 kasus pada bulan Maret, 29 kasus pada bulan April dan 305 kasus pada bulan Mei. Desa Beran menempati angka kejadian tertinggi sebanyak 141 kasus periode MaretMei 2015 dibandingkan Desa Grudo yang menempati 36 kasus. Salah satu kejadian diare di Desa Beran terbanyak adalah di Dusun Wareng yaitu 16 kasus dibanding Dusun Beran 1 sebanyak 7 kasus. ${ }^{[2]}$

Pemerintah kabupaten Ngawi telah mendeklarasikan Open Defecation Free (ODF) untuk mengatasi masalah diare. Pemerintah kabupaten Ngawi mentargetkan angka cakupan kepemilikan jamban sebesar $85 \%$ dan $15 \%$ menumpang jamban tetangga ataupun di toilet umum. Demi tercapainya Ngawi Bebas Buang Air Besar di sembarang tempat, maka pemerintah kabupaten Ngawi mengeluarkan Peraturan Bupati No. 4 Tahun 2014 tentang Pedoman Pengawasan dan Larangan BAB di Sembarang Tempat. Dusun Wareng di Desa Beran Kecamatan Ngawi Kota sudah ditetapkan sebagai Dusun ODF. Akan tetapi kejadian diare masih tinggi, berdasarkan hal tersebut penulis ingin mengetahui apakah ada hubungan antara kualitas fisik jamban keluarga dengan kejadian diare di Dusun Wareng, Desa Beran Kecamatan Ngawi. ${ }^{[2]}$

\section{METODE PENELITIAN}

Jenis penelitian yang digunakan adalah penelitian analitik. Desain studi yang digunakan adalah cross sectional. Populasi dalam penelitian ini adalah seluruh kepala rumah tangga di Dusun Wareng, Desa Beran, Kecamatan Ngawi, Kabupaten Ngawi yang mempunyai jamban yaitu sebanyak 129 rumah dengan jumlah sampel 98 responden. Metode pengambilan sampel yang digunakan adalah Cluster Sampling. Penelitian ini dilaksanakan di Dusun Wareng, Desa Beran Kecamatan Ngawi Kabupaten Ngawi pada September-Oktober 2015. Variabel independen (variabel bebas) dalam penelitian ini kualitas fisik jamban keluarga. Sedangkan variabel dependen (variabel terikat) dalam penelitian ini adalah kejadian diare. Alat ukur yang digunakan dalam penelitian ini berupa lembar checklist. Data yang diperoleh dianalisis dengan chi square. 
HASIL DAN PEMBAHASAN

\section{A. Kualitas Jamban di Dusun Wareng, Desa Beran}

Kualitas jamban di Dusun Wereng Desa Beran dapat dilihat pada tabel di bawah ini :

Tabel 1. Kualitas Fisik Jamban

\begin{tabular}{clcc}
\hline No. & Kualitas Fisik Jamban & $\mathbf{f}$ & \% \\
\hline 1. & Sehat & 63 & 64,3 \\
2. & Tidak Sehat & 35 & 35,7 \\
\hline \multicolumn{2}{r}{ Total } & $\mathbf{9 8}$ & $\mathbf{1 0 0 , 0}$ \\
\hline
\end{tabular}

Hasil penelitian menunjukkan bahwa sebagian besar responden yang memiliki kualitas fisik jamban sehat (64,3\%). Suatu jamban disebut sehat untuk daerah pedesaan apabila memenuhi persyaratan yaitu, tidak mengotori permukaan tanah di sekeliling jamban, tidak mengotori air permukaan di sekitarnya, tidak mengotori air tanah, tidak terjangkau oleh serangga terutama lalat dan kecoa dan binatang lainnya, tidak menimbulkan bau, mudah digunakan dan dipelihara, murah dan dapat diterima oleh pemakainya. ${ }^{[3]}$ Oleh karena itu, promosi tentang jamban sehat perlu dilakukan oleh dinas kesehatan setempat agar masyarakat memahami pentingnya kesehatan dalam hal pembuangan kotoran demi menghindari resiko penularan penyakit yang disebabkan oleh tinja.

\section{B. Kejadian Diare di Dusun Wareng, Desa Beran}

Kejadian diare di Dusun Wereng Desa Beran dapat dilihat pada tabel di bawah ini :

Tabel 2. Kejadian Diare

\begin{tabular}{crcc}
\hline No. & \multicolumn{1}{c}{ Kejadian diare } & f & \% \\
\hline 1. & Diare & 16 & 16,3 \\
2. & Tidak Diare & 82 & 83,7 \\
\hline \multicolumn{2}{r}{ Total } & $\mathbf{9 8}$ & $\mathbf{1 0 0 , 0}$ \\
\hline
\end{tabular}

Hasil penelitian menunjukkan bahwa sebagian besar responden tidak mengalami diare selama tiga bulan terakhir (83,7\%). Menurut WHO (2006) Diare adalah buang air besar encer atau cair lebih dari tiga kali dalam sehari. ${ }^{[4]}$ Menurut Depkes RI (2006) penyebab utama tingginya diare dipengaruhi beberapa faktor yaitu infeksi, alergi, keracunan, faktor perilaku dan lingkungan. Diare dapat disebabkn oleh beberapa hal, antara lain, pertama infeksi dapat diawali dengan adanya mikororganisme 
yang masuk ke dalam saluran pencernaan yang berkembang dalam usus, agentnya adalah bakteri, parasit. Kedua, alergi dimana tubuh tidak tahan makanan tertertu, seperti laktosa yang terkandung dalam susu sapi. Ketiga, keracunan dapat menyebabkan diare dari bahan kimia, serta keracunan oleh bahan yang dikandung dan diproduksi oleh makluk hidup, seperti sayuran, buah-buahan, alga, dan ikan. Keempat, faktor perilaku yang tidak menerapkan kebiasaan cuci tangan, buang air besar di sungai, sedangkan. Kelima, faktor lingkungan adalah ketersediaan air bersih yang tidak memadai, kurangnya ketersediaan jamban, dan kebersihan lingkungan. ${ }^{[5]}$

\section{Analisis Hubungan Kualitas Fisik Jamban Dengan Kejadian Diare}

Hasil analisis bivariat dalam penelitian ini ditunjukkan dalam tabel di bawah ini :

Tabel 3. Hasil Analisis Bivariat

\begin{tabular}{lccccc}
\hline \multirow{2}{*}{$\begin{array}{l}\text { Kualitas Fisik } \\
\text { Jamban }\end{array}$} & \multicolumn{4}{c}{ Kejadian Diare } & \multirow{2}{*}{ Nilai $\mathbf{p}$} \\
\cline { 2 - 5 } & $\mathbf{c}$ & $\%$ & $\mathbf{f}$ & $\%$ & \\
\hline Sehat & 12 & 19,0 & 51 & 81,0 & \multirow{2}{*}{0,011} \\
Tidak Sehat & 4 & 11,4 & 31 & 88,6 & \\
\hline
\end{tabular}

Analisis bivariat dalam penelitian ini menggunakan uji chi square. Hasil penelitian menunjukkan bahwa dari 63 responden yang mempunyai kualitas jamban sehat ada 12 responden yang mengalami Diare (19\%) dan 51 responden yang tidak mengalami Diare (81\%). Sedangkan dari 35 responden yang mempunyai kualitas jamban yang tidak sehat, ada 4 responden yang menderita Diare $(11,4 \%)$ dan 31 responden yang tidak menderita Diare (88,6\%). Hasil uji statistik menunjukan tidak ada hubungan antara variabel kualitas fisik jamban dengan variabel kejadian diare $(p=0,328)$.

Hasil penelitian ini tidak sesuai dengan penelitian yang dilakukan di Rembang yang menunjukkan bahwa terdapat hubungan sanitasi jamban dengan kejadian diare $(p=0,032) \cdot{ }^{[6]}$ Hasil penelitian ini sesuai dengan hasil penelitian Anjar bahwa terdapat hubungan antara sanitasi jamban dengan kejadian diare pada anak balita di Desa Blimbing, Kecamatan Sambirejo, Saragen. Menurut Notoatmodjo (2003) bahwa pembuangan tinja yang di sungai dapat menularkan penyakit. Tinja yang dibuang dalam keadaan terbuka dapat digunakan lalat untuk bertelur. Lalat berperan penting dalam penularan penyakit salah satunya penyakit diare melalui 
tinja yang hinngap di kotoran manusia dan makanan manusia. ${ }^{[3]}$

Berdasarkan hal tersebut, maka ada baiknya promosi tentang jamban sehat tetap dilakukan agar penyakit diare tidak berkembang dan derajat kesehatan masyarakat meningkat.

\section{SIMPULAN DAN SARAN}

\section{Simpulan}

1) Sebagian besar rumah tangga di Dusun Wareng ,Desa Beran memiliki kualitas jamban keluarga dengan kriteria sehat.

2) Sebagian kecil rumah tangga di Dusun Wareng, Desa Beran pernah mengalami diare selama 3 bulan terakhir periode bulan Juli-September. Kejadian diare kemungkinan disebabkan oleh makanan dan personal hygine yang buruk.

3) Tidak ada hubungan antara kualitas fisik jamban keluarga dengan kejadian Diare di Dusun Wareng Desa Beran Kecamatan Ngawi, Kabupaten Ngawi.

\section{Saran}

Dinas Kesehatan dapat terus mempromosikan pentingnya Jamban Sehat terutama ditekankan pada perlunya ventilasi pada rumah jamban dan lantai jamban dibuat kedap air untuk menghindari pencemaran dan penularan penyakit kepada masyarakat agar masyarakat selalu memperhatikan kualitas jamban keluarga yang dimiliki.

\section{DAFTAR PUSTAKA}

[1] Sander M. Hubungan Faktor Sosio Budaya dengan Kejadian Diare di Desa Candinegoro Kecamatan Wonoayu Sidoarjo. Jurnal Medika. 2005: 2 (2): 163-193.

[2] Dinas Kesehatan Kabupaten Ngawi. Profil Kesehatan Ngawi 2013. Ngawi : Dinas Kesehatan Kabupaten Ngawi, 2014.

[3] Notoadmodjo S. Prinsip-Prinsip Dasar Kesehatan Masyarakat. Jakarta:

PT Rineka Cipta; 2003

[4] WHO. Pengertian Diare dan Pencegahan Diare. Jakarta: PT EGC; 2006

[5] Indonesia. Buku Pedoman Pelaksanaan Program P2 Diare. Depkes RI: Ditjen PPM dan PL; 2006

[6] Siti Humairoh Sa'diyah, Prehatin Trirahayu Ningrum, Ellyke. Faktor yang Berhubungan dengan Kejadian Diare di Desa Rembang Kecamatan Rembang Tahun 2014. Artikel IImiah Hasil Penelitian Mahasiswa Universitas Jember. 2015:1-7. 


\section{PEDOMAN PENULISAN NASKAH JKM}

Jurnal Kesehatan Masyarakat (JKM) STIKES Cendekia Utama Kudus menerima naskah hasil-hasil riset, artikel ilmiah, studi/ analisa kritis, skripsi, tesis, disertasi dan tulisan ilmiah lain di bidang kesehatan masyarakat.

Naskah adalah karya asli penulis/ peneliti, bukan plagiat, saduran atau terjemahan karya penulis/ peneliti lain.

Naskah khusus ditujukan kepada Jurnal Kesehatan Masyarakat (JKM) STIKES Cendekia Utama Kudus, belum pernah dipublikasikan di media lain. Naskah yang dikirim harus disertai surat persetujuan publikasi dan surat pengantar yang ditandatangani peneliti/ penulis.

\section{Komponen naskah:}

$\checkmark$ Judul, ditulis maksimal 150 karakter, huruf Book Antiqua, ukuran 13, spasi 1

$\checkmark \quad$ Identitas penulis, ditulis setelah judul. Terdiri atas nama (tanpa gelar), alamat tempat kerja, nomor telepon/hp dan alamat email.

$\checkmark$ Abstrak dalam bahasa Indonesia dan bahasa Inggris, maksimal 200 kata, disusun dalam satu alinea, berisi masalah, tujuan, metode, hasil dan 3-5 kata kunci. Untuk naskah dalam bahasa Inggris, tidak perlu disertai abstrak dalam bahasa Indonesia.

$\checkmark$ Pendahuluan, tanpa subjudul, berisi latar belakang, sedikit tinjauan pustaka dan tujuan penelitian.

$\checkmark$ Metode penelitian, dijelaskan secara rinci, disain, populasi, sampel, sumber data, teknik/ instrumen pengumpul data, dan prosedur analisis data.

$\checkmark$ Hasil dan Pembahasan, mengurai secara tepat dan argumentatif hasil penelitian, kaitan hasil dengan teori yang sesuai dan sistematis.

$\checkmark$ Tabel atau gambar. Tabel, diberi nomor sesuai urutan penyebutan dalam teks, ditulis 1 (satu) spasi, ukuran 11. Judul singkat, padat dan jelas, terletak di atas tabel. Gambar, diberi nomor sesuai urutan penyebutan dalam teks. Judul singkat, padat dan jelas, terletak di bawah gambar.

$\checkmark$ Simpulan dan Saran. Simpulan menjawab masalah penelitian, pernyataan tegas. Saran logis, tepat guna dan tidak mengada-ada, dan ada keterkaitan dengan keberlanjutan penelitian 
$\checkmark$ Rujukan/ referensi ditulis sesuai aturan Vancouver, urut sesuai dengan pemunculan dalam keseluruhan teks, maksimal 25 rujukan dan 75 persen merupakan publikasi dalam 10 tahun terakhir.

Naskah sebanyak 15-25 halaman kuarto, batas atas-bawah-tepi kiri-tepi kanan (cm) : 4-3-4-3, spasi 1,5, jenis huruf: arial, ukuran 12, format microsoft word, dalam bentuk softfile dan 3 (tiga) eksemplar dalam bentuk print out.

Naskah dikirim ke alamat : Redaksi Jurnal Kesehatan Masyarakat (JKM) STIKES Cendekia Utama Kudus, Jl. Lingkar Raya Km.05 Jepang Mejobo Kudus 59381.

\section{Kontak langsung dapat melalui:}

$\checkmark$ Eko Prasetyo : 081228475759 / 081575435102

$\checkmark$ Sri Wahyuningsih : 085740572288

Naskah juga dapat dikirim melalui email : jkm.cendekiautama@gmail.com

\section{Contoh penulisan daftar pustaka :}

Artikel Jurnal Penulis Individu.

Sloan NL, Winikoff B, Fikree FF. An ecologic analysis of maternal mortality ratios. Stud Fam Plann 2001;32:352-355.

\section{Artikel Jurnal Penulis Organisasi}

Diabetes Prevention Program Research Group. Hypertension, insulin, and proinsulin in participants with impaired glucose tolerance. Hypertension.2002;40(5):679-86

\section{Artikel Jurnal di Internet}

Goodyear-Smith F and Arroll B, Contraception before and after termination of pregnancy: can we do it better? New Zealand Medical Journal, 2003, Vol. 116, No. 1186, <http://www.nzma.org.nz/journal/116-1186/683/content. pdf>, accessed Aug. 7, 2007.

\section{Buku Dengan Nama Editor sebagai penulisnya}

Lewis G, ed. Why mothers die 2000-2002: the confidential enquiries into maternal deaths in the United Kingdom. London: RCOG Press; 2004.

\section{Buku yang Ditulis Individu}

Loudon I. Death in childbirth. An international study of maternal care and maternal mortality 1800-1950.London: Oxford University Press, 1992. 


\section{Buku yang Ditulis Organisasi}

Council of Europe, Recent Demographic Developments in Europe 2004,Strasbourg, France: Council of Europe Publishing, 2005.

\section{Artikel dari Buletin}

Ali MM, Cleland $\mathrm{J}$ and Shah $\mathrm{IH}$, Condom use within marriage: a neglected HIV intervention, Bulletin of the World Health Organization, 2004, 82(3):180186.

\section{Paper yang Dipresentasikan dalam Pertemuan IImiah/Konferensi}

Kaufman J, Erli Z and Zhenming X, Quality of care in China: from pilot project to national program, paper presented at the IUSSP XXV International Population Conference, Tours, France, July 18-23, 2005.

\section{Bab dalam Buku}

Singh S, Henshaw SK and Berentsen K, Abortion: a worldwide overview, in: Basu AM, ed., The Sociocultural and Political Aspects of Abortion,Westport, CT, USA: Praeger Publishers, 2003, pp. 15-47.

\section{Data dari Internet}

U.S. Bureau of the Census, International Data Base, Country summary: China, 2007, <http://www.census.gov/ipc/ www/idb/country/chportal.html>, accessed Aug. 12, 2007.

\section{Disertasi}

Lamsudin R. Algoritma Stroke Gadjah Mada (Disertasi). Yogyakarta: Universitas Gadjah Mada. 1997

\section{Makalah dalam Surat Kabar}

Banzai VK, Beto JA. Treatment of Lupus Nephritis. The Jakarta Post 1989; Dec 8; Sect A.5(col 3)

\section{Kamus}

Ectasia. Dorland's Illustrated Medical Dictionary.27th ed. Philadelphia: Saunders, 1988;527 